\title{
Reconstituted fresh whole blood improves clinical outcomes compared with stored component blood therapy for neonates undergoing cardiopulmonary bypass for cardiac surgery: A randomized controlled trial
}

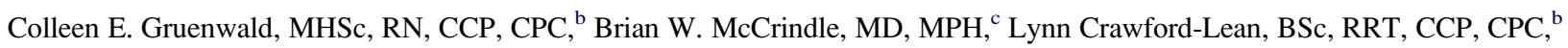
Helen Holtby, MD, ${ }^{\mathrm{d}}$ Christopher Parshuram, MBChB, D Phil, ${ }^{\mathrm{e}}$ Patricia Massicotte, MSc, MD, FRCPC, MHSc, ${ }^{\mathrm{f}}$ and Glen Van Arsdell, MD

Objective: This study compared the effects of reconstituted fresh whole blood against standard blood component therapy in neonates undergoing cardiac surgery.

Methods: Patients less than 1 month of age were randomized to receive either reconstituted fresh whole blood $(\mathrm{n}=31)$ or standard blood component therapy $(\mathrm{n}=33)$ to prime the bypass circuit and for transfusion during the 24 hours after cardiopulmonary bypass. Primary outcome was chest tube drainage; secondary outcomes included transfusion needs, inotrope score, ventilation time, and hospital length of stay.

Results: Patients who received reconstituted fresh whole blood had significantly less postoperative chest tube volume loss per kilogram of body weight $(7.7 \mathrm{~mL} / \mathrm{kg}$ vs $11.8 \mathrm{~mL} / \mathrm{kg} ; P=.03)$. Standard blood component therapy was associated with higher inotropic score (6.6 vs $3.3 ; P=.002)$, longer ventilation times (164 hours vs 119 hours; $P=.04$ ), as well as longer hospital stays (18 days vs 12 days; $P=.006$ ) than patients receiving reconstituted fresh whole blood. Of the different factors associated with the use of reconstituted fresh whole blood, lower platelet counts at 10 minutes and at the end of cardiopulmonary bypass, older age of cells used in the prime and throughout bypass, and exposures to higher number of allogeneic donors were found to be independent predictors of poor clinical outcomes.

Conclusions: Reconstituted fresh whole blood used for the prime, throughout cardiopulmonary bypass, and for all transfusion requirements within the first 24 hours postoperatively results in reduced chest tube volume loss and improved clinical outcomes in neonatal patients undergoing cardiac surgery.

Earn CME credits at

http://cme.ctsnetjournals.org

Morbidity and mortality during neonatal heart surgery for repair of congenital heart disease has dramatically improved over the past decade; however, it remains higher than in older children and adults. ${ }^{1}$ This is partly associated with the exaggerated disruptions of coagulation and the stimulation of the inflammatory response in neonates undergoing cardiopulmonary bypass (CPB) for congenital heart disease. ${ }^{1-3}$ The disturbances in coagulation that lead to postoperative bleeding in neonates are the result of interactions

\footnotetext{
From the Labatt Family Heart Centre, Departments of Cardiovascular Surgery, Perfusion, ${ }^{\mathrm{b}}$ Cardiology, ${ }^{\mathrm{c}}$ Anaesthesia, ${ }^{\mathrm{d}}$ Critical Care Medicine, ${ }^{\mathrm{e}}$ and Pediatrics, ${ }^{\mathrm{f}}$ The Hospital for Sick Children and The University of Toronto, Toronto, Ontario, Canada.

This work was funded by The Hospital for Sick Children Foundation.

Received for publication Jan 24, 2008; revisions received July 9, 2008; accepted for publication Aug 28, 2008.

Address for reprint: Colleen E. Gruenwald, MHSc, RN, CCP, CPC, Perfusion Services, The Hospital for Sick Children, 555 University Ave, Toronto, Ontario, Canada, M5G1X8 (E-mail: colleen.gruenwald@sickkids.ca).

J Thorac Cardiovasc Surg 2008; 136:1442-9

$0022-5223 / \$ 34.00$

Copyright (c) 2008 by The American Association for Thoracic Surgery

doi:10.1016/j.jtcvs.2008.08.044
}

between many mechanisms. These include factors such as hemostatic system immaturity, hemodilution, systemic inflammation, prolonged bypass times, and the use of deep hypothermic circulatory arrest (DHCA). ${ }^{4-7}$

Increased bleeding and allogeneic blood transfusion requirements have been shown to vary inversely with the age and size of infants requiring cardiac surgery. ${ }^{8}$ Transfusion of allogeneic blood products is associated with a number of adverse effects such as infectious agent transmission, the development of postoperative infections, and other transfusion reactions. ${ }^{9-12}$ Previous studies of the use of fresh whole blood to either prime the CPB circuit or meet postoperative transfusion requirements have reported conflicting results. ${ }^{13,14}$ No studies have compared the use of reconstituted fresh whole blood (RFWB) versus standard blood component therapy to prime the $\mathrm{CPB}$ circuit and replace postoperative blood loss within the first 24 hours after surgery. We sought to determine whether the use of RFWB during CPB and for the first 24 hours postoperatively would improve clinical outcomes compared with standard blood component therapy.

\section{METHODS}

\section{Study Design}

This prospective randomized controlled clinical trial was conducted from August 2001 until March 2005. Delays and scheduling conflicts 

Abbreviations and Acronyms
ACT = activated clotting time
CBS = Canadian Blood Services
$\mathrm{CCCU}=$ cardiac critical care unit
$\mathrm{CPB}=$ cardiopulmonary bypass
$\mathrm{DHCA}=$ deep hypothermic circulatory arrest
IL-8 = interleukin 8
$\mathrm{PRBC}=$ packed red blood cell
RFWB $=$ reconstituted fresh whole blood
$\mathrm{TNF}=$ tumor necrosis factor

initially created by the severe acute respiratory syndrome (SARS) epidemic (March 2002) as well as difficulties in coordinating operations, patient consent, and blood acquisition explain why a lengthier enrollment period was necessary. The surgeons were blinded to the patients' group randomization, whereas perfusion, anesthesia, and cardiac critical care unit (CCCU) staff were unblinded. Institutional research ethics board approval was granted at The Hospital for Sick Children, Toronto, Ontario, Canada, with written informed consent obtained from the legal guardian of each patient before enrollment into the study randomization. An independent safety committee oversaw the study with no member having any clinical responsibilities for any of the study subjects and no ties to any of the study investigators. Sixty-four patients met the inclusion criteria of being less than 1 month of age and scheduled for elective cardiac surgery requiring CPB. Exclusion criteria included emergency surgery and patients known to have a pre-existing coagulopathy. Subjects were randomized in blocks of 4 to 6 patients to receive either RFWB in the prime of the CPB circuit and for all transfusion requirements up to 24 hours postoperatively in the treatment group $(\mathrm{n}=31)$ or standard blood component therapy in the control group $(n=33)$. Required sample size was calculated on the basis of previous study of fresh whole blood versus component therapy. ${ }^{13}$ It was calculated that a sample size of 50 patients would detect a $50 \%$ reduction in chest tube volume loss with alpha of. 05 and power of $90 \%$.

\section{Blood Product Preparation}

All blood products used for both study groups were collected from random volunteer donors and processed according to Canadian Blood Services (CBS) standard operating procedure. Routine testing for infectious agents was performed on all donated blood before issue from CBS. In both study groups, CBS required that all donor blood be separated into components (red blood cells, random donor platelets, and fresh frozen plasma) immediately after collection and leukocyte reduced by filtration before storage. All donor blood was collected in bags containing the anticoagulant solution citrate phosphate double dextrose. AS-3 (Nutricel; Haemonetics, Braintree, Mass) preservative was added to packed red blood cell (PRBC) components and stored at $1^{\circ} \mathrm{C}$ to $6^{\circ} \mathrm{C}$. AS-3 was subsequently removed from all PRBC before release from the Blood Transfusion Laboratory of The Hospital for Sick Children as per standard hospital protocol for neonatal patients. All plasma was frozen within 8 hours of donation and stored at $-18^{\circ} \mathrm{C}$ or less. Platelets were continually agitated during storage at $20^{\circ} \mathrm{C}$ to $24^{\circ} \mathrm{C}$ after separation from platelet-rich plasma by hard spin centrifugation.

When patients were randomized to the treatment arm, CBS was notified and designated 2 units of ABO-compatible single random donor blood from two separate donors to be released to the hospital's blood transfusion laboratory. On the morning of the operation, one of the RFWB units was prepared by reconstituting the components from the single donor that had been processed as previously described. The second unit of RFWB was prepared and released as required. All RFWB units were collected 2 days before the morning of the operation. Patients in the control group received
ABO-compatible stored blood components as per standard hospital protocol. PRBC and platelets were irradiated on the morning of the operation, before either reconstitution or release as individual components, depending on the randomization. Platelet components used in the control group were random single donor platelets collected 2 to 5 days (median 4 days) before surgery that were either in their original state or further concentrated at the discretion of the attending anesthesiologist.

\section{Anesthesia Management (Intraoperative)}

Anesthesia was induced with sodium thiopentone (up to $5 \mathrm{mg} / \mathrm{kg}$ ) and fentanyl $(20 \mu \mathrm{g} / \mathrm{kg})$ and muscle relaxation with pancuronium $(0.1 \mathrm{mg} / \mathrm{kg})$. An appropriate-sized endotracheal tube was placed and anesthesia was maintained with isoflurane in air and oxygen with supplemental doses of fentanyl as clinically indicated. All patients were given aprotinin (Trasylol Bayer AG, Leverkusen, Germany) before CPB at a dose of 50,000 KIU/kg after a test dose of 1,000 KIU/kg. Cefazolin (Ancef; GlaxoSmithKline, London, United Kingdom), $40 \mathrm{mg} / \mathrm{kg}$, was given for wound prophylaxis. Patients undergoing DHCA were given methylprednisolone $30 \mathrm{mg} / \mathrm{kg}$. Anticoagulation was initiated with a dose of $300 \mathrm{IU}$ of heparin sulfate per kilogram body weight with a target activated clotting time (ACT) of more than 480 seconds before the institution of CPB. Additional heparin was given during CPB when the ACT was less than 450 seconds. Protamine sulfate was given in a 1:1 ratio to reverse anticoagulation based on the initial heparin dose, and additional doses were given based on the subsequent ACT.

\section{Perfusion Management (CPB)}

The CPB circuit priming solution was composed as follows: electrolyte solution (Plasma-Lyte 148; Baxter Healthcare, Deerfield, Ill), mannitol 0.25 $\mathrm{g} / \mathrm{kg}$, sterile water $50 \mathrm{~mL}$, and $25 \%$ albumin $75 \mathrm{~mL}$. The randomized blood product, either RFWB or PRBC component, was added to achieve a CPB hematocrit value of $22 \%$ to $24 \%$. Cefazolin, $40 \mathrm{mg} / 250 \mathrm{~mL}$ of prime volume, $10 \%$ calcium chloride, and heparin sulfate, $2 \mathrm{IU} / \mathrm{mL}$ of prime, were also added. The total volume was approximately $400 \mathrm{~mL}$. Aprotinin was added to the prime at a dose of $100,000 \mathrm{KIU} / 100 \mathrm{~mL}$ of prime volume after the test dose was safely given. Ultrafiltration was used during CPB to remove any excess fluid added throughout the surgical procedure.

Blood flow was maintained on CPB at 120 to $150 \mathrm{~mL} / \mathrm{kg}$ body weight. Patients undergoing DHCA were actively cooled to a rectal temperature of $15^{\circ} \mathrm{C}$ and $\mathrm{pH}$-stat blood gas management was used during cooling. All other patients were allowed to passively cool to $34^{\circ} \mathrm{C}$ body temperature and alpha-stat blood gas management was used throughout.

Myocardial protection was achieved with blood cardioplegia using a blood and crystalloid mixture at a 2:1 ratio. Additional mannitol was given before aortic crossclamp removal at a dose of $0.5 \mathrm{mg} / \mathrm{kg}$. Patients received blood products, either RFWB or PRBC, to maintain a hematocrit value between $22 \%$ and $24 \%$ during $\mathrm{CPB}$ and to reach a target hematocrit value of $28 \%$ in acyanotic patients and $32 \%$ in cyanotic patients before weaning from $\mathrm{CPB}$. Patients randomized to receive component blood therapy received 1 unit of fresh frozen plasma with heparin sulfate $(2 \mathrm{IU} / \mathrm{mL})$ added before aortic crossclamp removal. All patients underwent modified ultrafiltration after CPB.

After CPB, control patients were given components for volume replacement according to the following transfusion guidelines: PRBC when the hematocrit value was less than $28 \%$ (acyanotic patients) or $32 \%$ (cyanotic patients), platelets $(1 \mathrm{U} / 6 \mathrm{~kg})$ when the platelet count was less than $100,000 / \mathrm{mm}^{3}$, cryoprecipitate if the fibrinogen level was less than $1.0 \mathrm{~g} / \mathrm{L}$, and additional fresh frozen plasma for ongoing bleeding. Patients randomized to the treatment group received RFWB for hemostasis and volume replacement as required until both available units were used, after which standard blood component therapy was used according to the aforementioned transfusion guidelines.

\section{Data Collection}

Arterial blood samples were obtained from all patients after the placement of the arterial line, 10 minutes after to the start of $\mathrm{CPB}$, before aortic 
crossclamp removal, at the end of $\mathrm{CPB}$, after protamine and at 4 and 24 hours in the CCCU. Additional blood samples were taken every 4 hours in the $\mathrm{CCCU}$ and results were used to guide transfusion protocols as previously described. Blood samples were analyzed for complete blood count, fibrinogen, and biochemistry. Interleukin 8 (IL-8) and tumor necrosis factor (TNF- $\alpha$ ) levels were measured at induction of anesthesia and 4 and 24 hours after arrival in the CCCU. IL- 8 and TNF- $\alpha$ levels were measured by immunometric assay (Immulite analyzer; Euro/DPC, Llanberis, United Kingdom). The surgeon gave a subjective assessment of intraoperative bleeding graded as mild, moderate, or severe before leaving the operating room. Chest tube drainage and hematocrit value within the first 24 hours after the $\mathrm{CCCU}$ admission were measured.

Blood transfusion during $\mathrm{CPB}$ and for 24 hours postoperatively was tabulated by the total volume and the type and number of blood product units transfused. The transfusion guidelines used in the CCCU were the same as those used immediately after CPB. An inotropic support score was calculated at 24 hours after arrival in CCCU by means of the following formula, using drug dosages expressed as micrograms per kilogram per minute: dopamine + dobutamine $+($ epinephrine $\times 100)+($ milrinone $\times$ 10). ${ }^{14}$ Total ventilation hours and CCCU and hospital length of stay were also compared.

\section{Statistical Analysis}

Data are described as frequencies, medians with ranges, and means with standard deviations as appropriate. Baseline characteristics and outcomes were compared with Fisher's exact tests, $\chi^{2}$ tests, Kruskal-Wallis analysis of variance, and the Student $t$ tests as appropriate. To account for repeated measures and multiple comparisons, differences between groups for serial measures of laboratory and inflammatory marker variables were tested in multivariable mixed linear regression modeling using a compound symmetry covariance structure. The compound symmetry covariance structure calculates and accounts for the correlation between multiple observations on the same patients. Multivariable regression models were created using maximum likelihood estimates to determine the independent effect of age of blood cells in the prime, allogeneic donor exposures, and platelet count on medical outcome of interest while accounting for correlation between these variables. Given a skewed distribution for the inflammatory marker variables, the distribution was normalized with a logarithmic transformation. All analyses were performed with SAS statistical software version 9.1 (SAS Institute, Inc, Cary, NC).

\section{RESULTS \\ Clinical Outcomes}

Experimental groups were similar in terms of demographic and intraoperative characteristics (Tables 1 and 2). Norwood surgery and requirements for steroid were not found to affect the relationship between blood transfusions and surgical outcomes, even though they were unevenly distributed between groups. All patients survived to CCCU discharge. One patient in the RFWB group died before hospital discharge on day 331 after surgery.

As a result of the study design, the component group had significantly higher mean blood donor unit exposures $(7 \pm 4$ units) than the RFWB group ( $3 \pm 2$ units) when both CPB and postoperative blood transfusion requirements were included $(P<.0001)$.

Blood cells used in the prime were significantly older in the component group ( $14 \pm 8$ days) than in the RFWB group ( 2 days) $(P<.0001)$. There was no significant difference between the two groups in the median total volume trans-
TABLE 1. Baseline characteristics

\begin{tabular}{lccc}
\hline & $\begin{array}{c}\text { RFWB group } \\
(\mathbf{n}=\mathbf{3 1})\end{array}$ & $\begin{array}{c}\text { Control group } \\
(\mathbf{n}=\mathbf{3 3})\end{array}$ & $\boldsymbol{P}$ value \\
\hline Gender, No. (\%) & & & \\
$\quad$ Male & $19(61)$ & $17(52)$ & 0.44 \\
$\quad$ Female & $12(39)$ & $16(48)$ & \\
Age (d) & $15 \pm 10$ & $14 \pm 11$ & 0.65 \\
Surgeon, No. (\%) & & & \\
1 & $23(74)$ & $24(73)$ & 0.90 \\
2 & $3(10)$ & $3(9)$ & \\
3 & $5(16)$ & $6(18)$ & \\
Operation type, No. (\%) & & & 0.60 \\
Norwood & $6(19)$ & $10(30)$ & \\
Arterial switch & $19(61)$ & $17(52)$ & \\
Truncus repair & $2(6)$ & $2(6)$ & \\
Tetralogy repair & $0(0)$ & $1(3)$ & \\
TAPVD repair & $1(3)$ & $0(0)$ & \\
$\quad$ VSD, Coarct & $3(10)$ & $3(9)$ & \\
Weight (kg) & $3.5 \pm 0.6$ & $3.4 \pm 0.4$ & 0.80 \\
\hline
\end{tabular}

$R F W B$, Reconstituted fresh whole blood; $T A P V D$, total anomalous pulmonary venous drainage; $V S D$, ventricular sseptal defect; Coarct, coarctation.

fused within the study period $(93[24-319] \mathrm{mL} / \mathrm{kg}$ in the RFWB group vs 69 [26-271] mL/kg in the control group; $P=.55$ ). Fourteen patients in the RFWB group received additional blood component therapy after the 2 allotted units of RFWB were used.

The component group had significantly higher median chest tube loss $(11.8[4.0-44.1] \mathrm{mL} / \mathrm{kg})$ than the RFWB group $(7.7[2.0-34.6] \mathrm{mL} / \mathrm{kg})$ over the first 24 hours after CCCU admission $(P=.03)$ (Table 3). There was no significant difference in the measured hematocrit value of chest tube drainage between the two groups. The bleeding was described by the surgeon more frequently as moderate or severe in the component group $(27 / 31,82 \%)$ than in the RFWB group $(17 / 33,55 \% ; P=.03)$. There was a statistically significant correlation between surgeon's assessment of bleeding and postoperative chest tube volume loss $(P<.05)$.

The RFWB group had a significantly lower median inotropic score $(3.3 ; 0-9.9)$ at 24 hours in the CCCU than did the component group $(6.6 ; 0-14.9 ; P=.002)$.

TABLE 2. Intraoperative characteristics of RFWB group versus component therapy (controls)

\begin{tabular}{lccc}
\hline & $\begin{array}{c}\text { RFWB } \\
(\mathbf{n = 3 1})\end{array}$ & $\begin{array}{c}\text { Control } \\
(\mathbf{n}=\mathbf{3 3})\end{array}$ & $\begin{array}{c}\boldsymbol{P} \\
\text { value }\end{array}$ \\
\hline Mean CPB time (min \pm SD) & $136 \pm 58$ & $126 \pm 41$ & .42 \\
Mean aortic crossclamp time (min $\pm \mathrm{SD})$ & $79 \pm 26$ & $73 \pm 30$ & .43 \\
Patients with DHCA & $12(39 \%)$ & $15(45 \%)$ & .59 \\
Arterial switch operation with DHCA & 2 & 2 & \\
Median circulatory arrest time (min) & $8(3-27)$ & $11(1-38)$ & .68 \\
Norwood operation with SCP & 5 & 9 & \\
Mean OR time (min \pm SD) & $397 \pm 84$ & $398 \pm 89$ & .98 \\
\hline
\end{tabular}

$\overline{R F W B \text {, Reconstituted fresh whole blood; } C P B \text {, cardiopulmonary bypass; } S D \text {, standard }}$ deviation; $O R$, operating room; $D H C A$, deep hypothermic circulatory arrest; $S C P$, selective cerebral perfusion. 
TABLE 3. Clinical outcomes of RFWB group versus component therapy (controls)

\begin{tabular}{|c|c|c|c|}
\hline & $\begin{array}{c}\text { RFWB } \\
(\mathbf{n}=\mathbf{3 1})\end{array}$ & $\begin{array}{l}\text { Control } \\
(\mathbf{n}=\mathbf{3 3}) \\
\end{array}$ & $\begin{array}{c}P \\
\text { value }\end{array}$ \\
\hline \multicolumn{4}{|l|}{ Primary outcome measures } \\
\hline $\begin{array}{l}\text { Chest tube loss } 0-4 \mathrm{~h} \\
\text { CCCU, } \mathrm{mL} / \mathrm{kg} \text { (range) }\end{array}$ & $7.1(0.6-30.0)$ & $5.7(1.8-45.6)$ & .76 \\
\hline $\begin{array}{l}\text { Chest tube loss 4-24 h } \\
\text { CCCU, } \mathrm{mL} / \mathrm{kg} \text { (range) }\end{array}$ & $7.7(2.0-34.6)$ & $11.8(4.0-44.1)$ & .03 \\
\hline $\begin{array}{l}\text { Bleeding assessed as } \\
\text { moderate or severe }\end{array}$ & $17(55 \%)$ & $27(82 \%)$ & .03 \\
\hline \multicolumn{4}{|l|}{ Secondary outcome measures } \\
\hline $\begin{array}{l}\text { Inotropic support score } \\
\text { (ISS) at } 4 \mathrm{~h} \mathrm{CCCU}\end{array}$ & $6.6(0-20.0)$ & $9.5(0-20.0)$ & .53 \\
\hline $\begin{array}{l}\text { Inotropic support score } \\
\text { (ISS) at } 24 \mathrm{~h} \mathrm{CCCU}\end{array}$ & $3.3(0-9.9)$ & $6.6(0-14.9)$ & .002 \\
\hline $\begin{array}{l}\text { Ventilation in hours, } \\
\text { median (range) }\end{array}$ & $119(28-480)$ & $164(54-912)$ & .04 \\
\hline $\begin{array}{l}\text { CCCU LOS in days, } \\
\text { median (range) }\end{array}$ & $5(3-20)$ & $7(1-39)$ & .17 \\
\hline $\begin{array}{l}\text { Hospital LOS in days, } \\
\text { median (range) }\end{array}$ & $12(6-36)$ & $18(7-79)$ & .02 \\
\hline \multicolumn{4}{|l|}{ Transfusion characteristics } \\
\hline $\begin{array}{l}\text { Blood produce exposure, } \\
\text { mean units } \pm \mathrm{SD}\end{array}$ & $3.2 \pm 1.9$ & $6.9 \pm 3.8$ & $<.0001$ \\
\hline $\begin{array}{l}\text { Transfusion requirements } \\
\text { postop, } \mathrm{mL} / \mathrm{kg} \text { (range) }\end{array}$ & $33(0-177)$ & $43(4-160)$ & .55 \\
\hline $\begin{array}{l}\text { Age of donor blood } \\
\text { products, days }\end{array}$ & $1.9 \pm 0.3$ & $13.6 \pm 7.7$ & $<.0001$ \\
\hline
\end{tabular}

$R F W B$, Reconstituted fresh whole blood; $C C C U$, cardiac critical care unit; $L O S$, length of stay; $S D$, standard deviation.

The median total ventilation hours or time to first extubation was significantly reduced in the RFWB group when compared with the component group (119 [28-480] hours vs 164 [54-192] hours; $P=.04$ ).

There was no significant difference in the incidence of postoperative infections $(6 / 33[18 \%]$ in the component group vs $3 / 31[10 \%]$ in the RFWB group $[P=.48])$. Infections were either surgical site or blood-borne infections and included a positive culture.

The component group patients had a somewhat longer median CCCU length of stay (7 (1-39] days) than the patients in the RFWB group (5 [3-20] days; $P=.17$ ), albeit not significant. The median hospital length of stay in days for the survivors was significantly longer for the component group patients than for the RFWB group patients (18 [7-79] days vs 12 [6-36] days; $P=.006$ ) (Table 3 ).

The proportion of patients undergoing the Norwood operation was somewhat unequal between groups. A subanalysis including patients undergoing the Norwood operation only was performed (Table 4), and it was found that the relationship between RFWB and improved postoperative outcomes cannot be attributed to the slightly higher number of Norwood patients in the control group versus the RFWB group.
Regression models corrected for the use of corticosteroids, deep hypothermia, or staff surgeon did not alter the difference between improved clinical outcomes and the use of RFWB.

\section{Laboratory Measurements}

At induction, all patients had similar values for arterial blood gases, fibrinogen, electrolytes, magnesium, calcium, glucose, lactate, and hematologic indices (Figure 1). Lactate, potassium, and calcium levels were significantly higher in the CPB circuit prime in the component group $(P<.001)$. Although statistical differences were observed at sporadic time points in sodium, calcium, magnesium, glucose, and bicarbonate, no clinically relevant differences were observed between groups. There were no significant differences between groups at any time in colloid osmotic pressure, base deficit, $\mathrm{pH}$, and white cell count.

ACT was significantly higher in the component group at the time of aortic crossclamp removal $(P=.001)$. Fibrinogen levels were significantly higher in the component group after protamine $(P=.002)$ but remained similar across groups thereafter. Serum potassium level was significantly higher in the component group in the $\mathrm{CPB}$ circuit prime $(P<.0001)$ after 10 minutes of CPB $(P=.001)$, at the time of aortic crossclamp removal $(P=.008)$, and at the end of CPB $(P=.004)$. Hematocrit level was significantly higher in the component group after 10 minutes of $\mathrm{CPB}$ $(P=.0001)$ and at the end of CPB $(P<.0001)$ and in the postprotamine period $(P=.006)$, with similar findings for hemoglobin (data not shown). Platelet count was significantly lower in the component group after 10 minutes of CPB $(P=.02)$ and at the end of CPB $(P=.006)$.

Induction values for the markers of systemic inflammation, IL-8, and TNF- $\alpha$, were similar between groups $(P=.59$ for IL- $8 ; P=.18$ for TNF- $\alpha$ ). There was a significant increase in both markers measured at 4 hours after $\mathrm{CPB}$ and 24 hours after CBP, with a significantly greater increase seen in the component group compared with the RFWB group ( +84 vs RFWB at 4 hours [95\% confidence interval: $38-112$ ], $P=.003$ for IL- $8 ;+10$ vs RFWB at 4 hours [95\% confidence interval: $2-15], P=.02$ for TNF- $\alpha$ ).

\section{Age of Cells in Prime, Allogeneic Donor Exposures, and Platelet Count at the End of Bypass}

The use of RFWB as described in the Methods section affects 3 important parameters of blood transfusion: the age of infused cells, the number of allogeneic donor exposures, and the platelet count during bypass. Because the effect of RFWB is likely multifactorial in nature, further analyses were performed to quantify the relative effect of each component. In univariate analysis, chest tube loss at 24 hours in $\mathrm{CCCU}$, inotropic score at 24 hours, duration of ventilation, and hospital stay were all found to be significantly associated with age of blood product given in the 
TABLE 4. Demographic, surgical variables and clinical outcomes of RFWB group versus component therapy (controls) for Norwood patients only

\begin{tabular}{|c|c|c|c|}
\hline & $\operatorname{RFWB}(n=6)$ & Control $(\mathbf{n}=10)$ & $P$ value \\
\hline \multicolumn{4}{|l|}{ Primary outcome measures } \\
\hline Gender (male) & $1 / 6$ & $5 / 10$ & .20 \\
\hline Age $(d)$ & $10(3-30)$ & $9(5-33)$ & .79 \\
\hline Weight $(\mathrm{kg})$ & $3.5 \pm 0.5$ & $3.4 \pm 0.4$ & .28 \\
\hline Mean $\mathrm{CBP}$ time, $\min \pm \mathrm{SD}$ & $128 \pm 28$ & $122 \pm 23$ & .92 \\
\hline Mean aortic crossclamp time, $\min \pm \mathrm{SD}$ & $71 \pm 16$ & $61 \pm 11$ & .14 \\
\hline Median circulatory arrest time, $\min$ & $8(3-13)$ & $2(0-25)$ & .07 \\
\hline Mean OR time, $\min \pm \mathrm{SD}$ & $372 \pm 69$ & $402 \pm 39$ & .08 \\
\hline Chest tube loss 0-4 h CCCU, mL/kg (range) & $9.0(7.7-29.4)$ & $9.8(4.3-53.4)$ & .75 \\
\hline Chest tube loss 4-24 h CCCU, $\mathrm{mL} / \mathrm{kg}$ (range) & $10.3(4.3-33.1)$ & $13.4(4.1-51.7)$ & .45 \\
\hline Bleeding assessed as moderate or severe & $2 / 6$ & $9 / 10$ & .04 \\
\hline Inotropic support score (ISS) at $4 \mathrm{~h} \mathrm{CCCU}$ & $9.1(0.0-19.9)$ & $6.6(5.0-16.9)$ & .73 \\
\hline Inotropic support score (ISS) at $24 \mathrm{~h} \mathrm{CCCU}$ & $5.0(0.0-6.6)$ & $8.5(0.0-11.6)$ & .06 \\
\hline Ventilation in hours, median (range) & $264(163-361)$ & $170(121-380)$ & .39 \\
\hline CCCU LOS in days, median (range) & $12(7-19)$ & $9(6-16)$ & .36 \\
\hline Hospital LOS in days, median (range) & $22(17-36)$ & $21(16-25)$ & .42 \\
\hline Blood product exposure, mean units \pm SD & $3.8 \pm 1.5$ & $7.0 \pm 2.7$ & .01 \\
\hline Transfusion requirements postop, $\mathrm{mL} / \mathrm{kg}$ (range) & $103(0-177)$ & $37(16-102)$ & .13 \\
\hline Age of donor blood products in days & $1.5 \pm 0.5$ & $15.1 \pm 9.3$ & .001 \\
\hline
\end{tabular}

prime and throughout $\mathrm{CPB}$, exposure to allogeneic donors, and platelet count at the end of bypass. In multivariable analysis (Table 5), lower platelet count at the end of bypass, older age of blood product given in the prime and throughout $\mathrm{CPB}$, and exposure to higher number of allogeneic donors were found to be independent predictors of higher chest tube loss at 24 hours and longer duration of ventilation. Only lower platelet count at the end of bypass and exposure to higher number of allogeneic donors were independent predictors of higher inotropic score at 24 hours. Lower platelet count at the end of bypass and older age of blood cells given in the prime and throughout bypass were found to be independent predictors of longer duration of hospital stay. Of interest, the relationship observed between platelet counts at the end of CPB and clinical outcomes is replicated by platelet counts at 10 minutes during $\mathrm{CPB}$.

\section{Discussion}

Neonates undergoing CPB for open cardiac surgery are generally obligated to receive blood transfusions owing to perioperative bleeding exacerbated by pre-existing coagulation defects and by the use of CPB. ${ }^{6,8}$ There are risks to blood transfusion and morbidity associated with postoperative bleeding. ${ }^{9-11}$ Efforts should be made to reduce allogeneic donor exposure. The use of fresh whole blood has been shown to reduce postoperative bleeding in infant patients. However, recent transfusion medicine standards do not support its widespread usage. ${ }^{13,15}$ The preparation of the RFWB product used for our study followed the current CBS and hospital transfusion laboratory standard operating procedures, including duration of blood storage. The reconstituted product used in this study may be superior to tradi- tional fresh whole blood owing to pre-storage leukocyte depletion and the storage of platelets at room temperature. ${ }^{16,17}$ Pre-storage leukocyte depletion is a standard for blood component preparation in Canada, with the current filters reducing the number of leukocytes present in blood by $4 \operatorname{logs}\left(10^{-4}\right)$, a value below which it is believed that alloimmunization or suppression does not occur. ${ }^{18}$ Platelets stored at room temperature exhibit better hemostatic properties than when stored at cold temperatures, which is routine in traditional whole blood storage. ${ }^{19}$

The neonates who received RFWB had significantly improved clinical outcomes, including less postoperative chest tube volume loss during the first 24 hours in the CCCU, significantly lower inotropic scores, decreased ventilation time, and reduced hospital length of stay.

It was demonstrated by this study that three factors affected by the use of RFWB are independently contributing to these improved outcomes: a higher platelet count at 10 minutes and at the end of CPB, a reduced number of allogeneic donor exposures, and younger age of blood products.

Patients in the RFWB group were exposed to a significantly reduced number of donors, which was in part a result of the study design coupled with a reduction in postoperative chest tube volume loss. The significantly reduced inotropic score, ventilation time, and hospitalization in the RFWB patient group was shown to be independently associated with a lower number of donors exposures.

A higher platelet count at 10 minutes and at the end of CPB was associated with significantly reduced chest tube volume loss and is supported by other investigators. ${ }^{6}$ Therefore, the results indicate that it is important to use RFWB for priming the $\mathrm{CPB}$ circuit, as well as throughout CPB. 


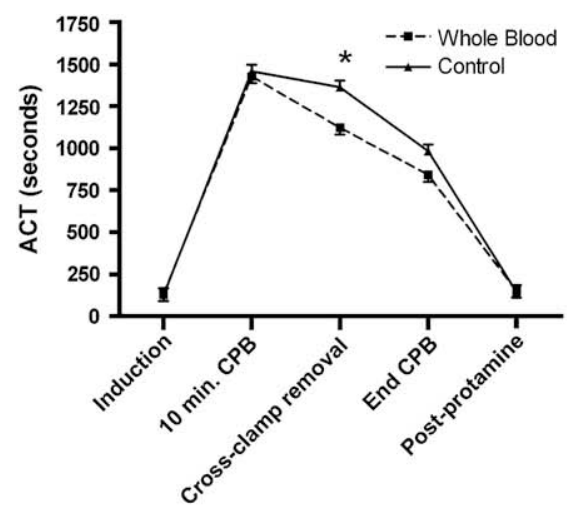

Time Category

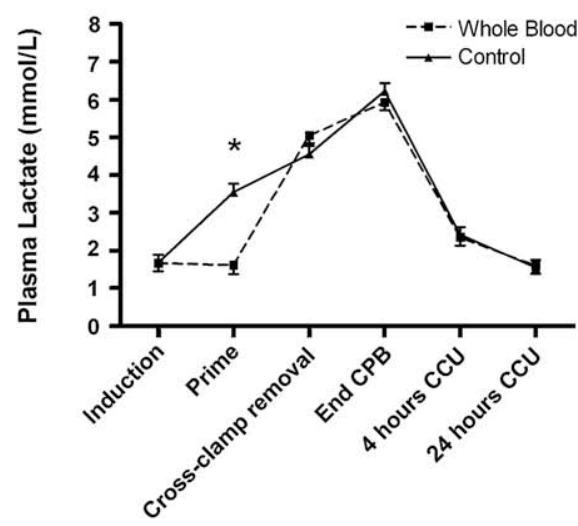

Time Category

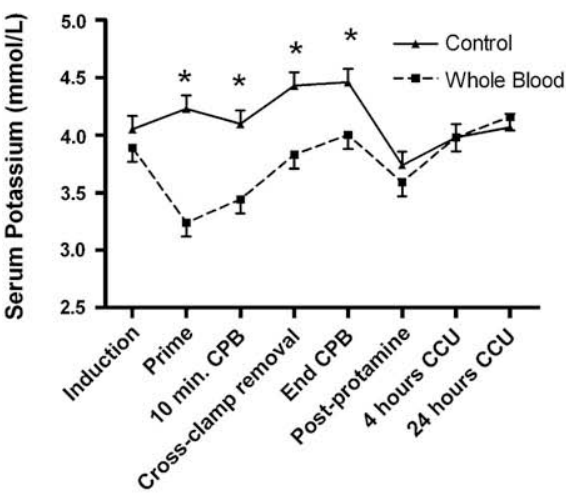

Time Category

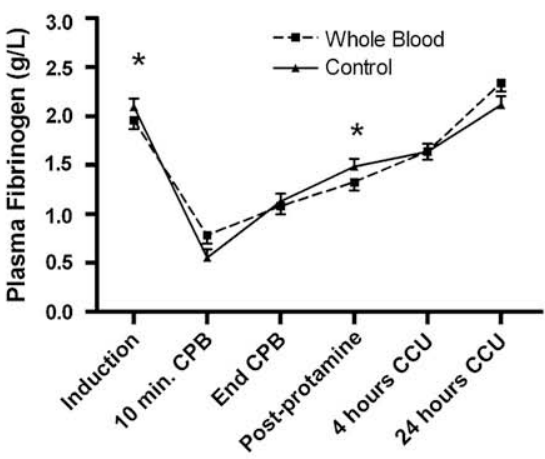

Time Category

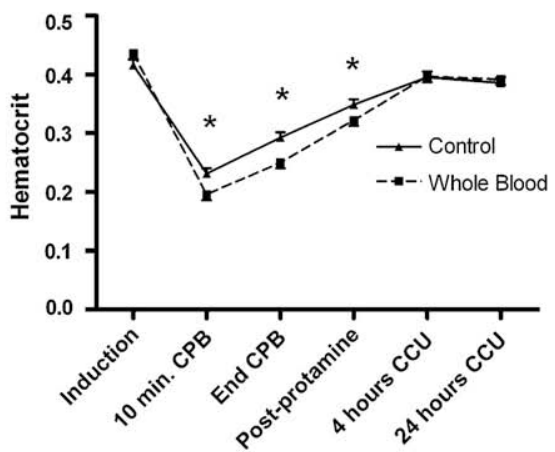

Time Category

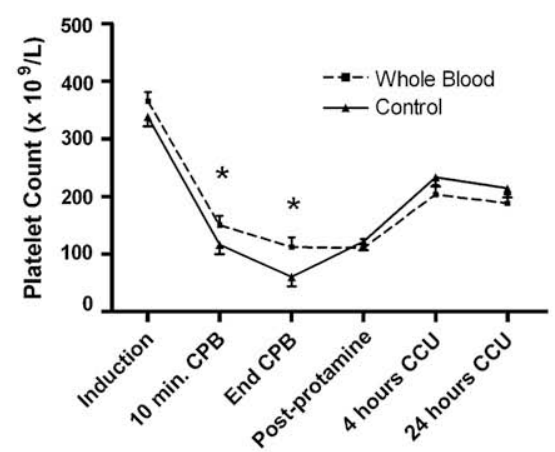

Time Category

FIGURE 1. Serial laboratory measurements. Only laboratory variables that showed a significant interaction between intervention assignment and time period are shown. Data presented are least square means with the error bar representing the standard error of the mean, derived from mixed linear regression analysis adjusted for repeated measures, with only significant $P$ values reported from the multivariable analysis. $* P<.05$. $A C T$, Activated clotting time; $C C C U$, cardiac critical care unit; $C P B$, cardiopulmonary bypass.

The median age of the PRBC components used in the control group was 14 days and the median age of the platelets was 4 days (current standard for CBS). An increase in the length of storage of PRBC has been associated with an increase in the risk of postoperative pneumonia and an increased duration of stay in the cardiac surgical population. ${ }^{20-22}$ Furthermore, the transfusion of platelets stored for less than 48 hours has been shown to be associated with larger increases in posttransfusion platelet increments and longer platelet transfusion intervals. ${ }^{23}$ The difference in the age of the blood used between the two study groups contributed to the improved clinical outcomes in the RFWB group.

Interestingly, this study observed that the markers of inflammation measured, IL- 8 and TNF- $\alpha$, experienced a significantly greater increase in the component group as compared with the RFWB group. Previous studies have shown 
TABLE 5. Independent effect of age of blood cells in the prime, allogeneic donor exposure and platelet count at the end of bypass on clinical outcomes

\begin{tabular}{|c|c|c|c|c|}
\hline & \multicolumn{3}{|c|}{ Univariate MLE analysis } & \multirow{2}{*}{$\begin{array}{c}\text { Multivariable } \\
P \text { value } \\
\end{array}$} \\
\hline & PE & SE & $P$ value & \\
\hline \multicolumn{5}{|l|}{ Higher chest tube loss at 24 hours } \\
\hline Lower platelet count at the end of bypass $\left(\times 10^{9} / \mathrm{L}\right)$ & -0.0026 & $(0.0004)$ & $<.0001$ & $<.0001$ \\
\hline Older age of blood product in prime (d) & 0.0120 & $(0.0010)$ & $<.0001$ & $<.0001$ \\
\hline Higher number of allogeneic donors exposure & 0.0241 & $(0.0024)$ & $<.0001$ & .06 \\
\hline \multicolumn{5}{|l|}{ Higher inotropic score at 24 hours } \\
\hline Lower platelet count at the end of bypass $\left(\times 10^{9} / \mathrm{L}\right)$ & -0.0029 & $(0.0012)$ & .02 & .004 \\
\hline Older age of blood product in prime (d) & 0.0087 & $(0.0029)$ & .003 & .10 \\
\hline Higher number of allogeneic donors exposure & 0.0310 & $(0.0064)$ & $<.0001$ & .005 \\
\hline \multicolumn{5}{|l|}{ Longer duration of ventilation $(\mathrm{h})$} \\
\hline Lower platelet count at the end of bypass $\left(\times 10^{9} / \mathrm{L}\right)$ & -0.0041 & $(0.0002)$ & $<.0001$ & $<.0001$ \\
\hline Older age of blood product in prime (d) & 0.0129 & $(0.0005)$ & $<.0001$ & $<.0001$ \\
\hline Higher number of allogeneic donors exposure & 0.0206 & $(0.0012)$ & $<.0001$ & $<.0001$ \\
\hline \multicolumn{5}{|l|}{ Longer duration of hospital stay $(\mathrm{d})$} \\
\hline Lower platelet count at the end of bypass $\left(\times 10^{9} / \mathrm{L}\right)$ & -0.0042 & $(0.0007)$ & $<.0001$ & $<.0001$ \\
\hline Older age of blood product in prime (d) & 0.0102 & $(0.0016)$ & $<.0001$ & $<.0001$ \\
\hline Higher number of allogeneic donors exposure & 0.0161 & $(0.0039)$ & $<.0001$ & .67 \\
\hline
\end{tabular}

Parameters are reported for the univariate associations while $P$ values are reported for both univariate and multivariable associations. $M L E$, Maximum likelihood estimate; $P E$, parameter estimate; $S E$, standard error.

that an IL-8 level measured after CPB in children is a marker of early postoperative morbidity. ${ }^{24}$

Results from this study are in contradiction with a previous randomized controlled trial of fresh whole blood versus component therapy. ${ }^{14}$ Mou and colleagues ${ }^{14}$ found no differences in postoperative outcomes between experimental groups, and some secondary clinical measures showed an advantage for the component therapy. A few major issues with the study design are to be considered when contrasting both studies. First, the use of fresh whole blood for priming the bypass circuit only while using component therapy for further transfusion requirements might have obscured the effect of fresh whole blood. Second, the use of blood (in both arms of the study) that had not been leukodepleted could offset gains made by using fresh whole blood. Finally, morbidity and mortality rates in the postoperative period might have confounded the results and overshadowed any improvements made with the use of fresh whole blood. Furthermore, another study by Manno and colleagues ${ }^{13}$ also found that the use of fresh whole blood for priming and for perioperative and postoperative requirements was associated with improved clinical outcomes, thus supporting the results of the current study.

While this study put forward the clinical advantages of using fresh whole blood in the context of neonatal cardiac surgery, logistical issues may prevent replicating this strategy in a routine context. Nonetheless, many features of a fresh reconstituted whole blood strategy show that they are independently associated with improved outcomes: fresher blood, smaller number of exposures, and higher platelet count during bypass. Many of these features can be obtained with this modified component therapy protocol even when single donor whole blood is unavailable. As such, when single donor RFWB is not practical, an alternative strategy may include the use of reconstituted fresh components from multiple donors. This may replicate the effect of RFWB without the challenge of obtaining single donor products. The addition of fresh platelets in the prime will achieve a higher platelet count on initiation of bypass and throughout surgery, which was found to be an important element of the effect of RFWB. Because this assumption is not yet supported by research, future studies could focus on methodologies to emulate the effect of RFWB using different techniques when RFWB is not available.

This study must be viewed in light of some limitations. The enrollment period had to be extended owing to logistic issues that meant only a limited proportion of eligible neonates could be enrolled in the study. However, the date of surgery was not found to be associated with clinical outcomes. Further, the age of red cells and platelets in the component therapy group was older than that used in other centers but was within acceptable CBS standard operating procedures. The assessment of blood loss in the postoperative period only took into account drainage from chest tubes and did not account for potential blood collecting in the pleural cavity or blood accumulating in the mediastinum for patients with open chests in the intensive care unit. Despite the fact that using chest tube volume loss as a surrogate for postoperative bleeding could underestimate total blood loss, there are no reasons to believe that this difference would be unevenly distributed between experimental groups. Finally, previous surgical studies have also used chest tube volume loss as a surrogate for postoperative bleeding in pediatric patients undergoing open cardiac surgery. 
In conclusion, this study advocates the use of single donor RFWB to prime the bypass circuit, throughout $\mathrm{CPB}$, and for transfusion requirements during the first 24 hours after surgery. This technique was associated with a significant reduction in chest tube volume loss for neonatal patients undergoing $\mathrm{CPB}$ for cardiac surgery. Furthermore, those patients who received RFWB had significantly better clinical outcomes, including decreased need for inotropic support, reduced ventilation time, and shorter hospital length of stay. In light of these data, adopting a modified practice of using platelets in the prime, fresher blood components, and limiting donor exposure could be highly beneficial.

We are grateful for the assistance from the many colleagues who participated in conducting this clinical trial. Specifically, we would like to thank the cardiac surgical team including the anesthesiologists, nurses, perfusionists, and surgeons, as well as the cardiac critical care team including the intensivists and nurses. In addition, the collaboration from the staff in the Blood Transfusion Laboratory at The Hospital for Sick Children and Canadian Blood Services made this study possible. We would also like to thank Rebecca Gurofsky, BSc, and Cedric Manlhiot, BSc, for their patience in assisting with the data analysis.

\section{References}

1. Jaggers JJ, Neal MC, Smith PK, Ungerleider RM, Lawson JH. Infant cardiopulmonary bypass: a procoagulent state. Ann Thorac Surg. 1999;68:513-20.

2. Kern FH, Morana NJ, Sears JJ, Hickey PR. Coagulation defects in neonates during cardioplulmonary bypass. Ann Thorac Surg. 1992;54:541-6.

3. Hovels-Gurich HH, Schumacher K, Vazquez-Jimenez JF, Qing M, Huffmeier U, Buding B, et al. Cytokine balance in infants undergoing cardiac operation. Ann Thorac Surg. 2002;73:601-9.

4. Guay J, Rivard G. Mediastinal bleeding after cardiopulmonary bypass in pediatric patients. Ann Thorac Surg. 1996;62:1955-60.

5. Andrew M, Vegh P, Johnston M, Bowker J, Ofosu F, Mitchell L. Maturation of the hemostatic system during childhood. Blood. 1992;80:1998-2005.

6. Williams GD, Bratton SL, Ramamoorthy C. Factors associated with blood loss and blood product transfusions: a multivariate analysis in children after openheart surgery. Anesth Analg. 1999;89:57-64.

7. Chan AK, Leaker M, Burrows FA, Williams WG, Gruenwald CE, Whyte L, et al. Coagulation and fibrinolytic profile of paediatric patients undergoing cardiopulmonary bypass. Thromb Haemost. 1997;77:270-7.
8. Williams GD, Bratton SL, Riley EC, Ramamoorthy C. Association between age and blood loss in children undergoing open heart operations. Ann Thorac Surg. 1998;66:870-6.

9. Schroeder ML. Transfusion-associated graft-versus-host disease. Br J Haematol. 2002;117:275-87.

10. Perrotta PL, Snyder EL. Non-infectious complications of transfusion therapy. Blood Rev. 2001;15:69-83.

11. Kleinman S, Caulfield T, Chan P, Davenport R, McFarland J, McPhedran S, et al. Toward an understanding of transfusion-related acute lung injury: statement of a consensus panel. Transfusion. 2004;44:1774-89.

12. Leal-Noval SR, Rincon-Ferrari MD, Garcia-Curiel A, Herruzo-Aviles A, CamachoLarana P, Garnacho-Montero J, et al. Transfusion of blood components and postoperative infection in patients undergoing cardiac surgery. Chest. 2001;119:1461-8.

13. Manno CS, Hedberg KW, Kim HC, Bunin GR, Nicolson S, Jobes D, et al. Comparison of the hemostatic effects of fresh whole blood, stored whole blood, and components after open heart surgery in children. Blood. 1991;77:930-6.

14. Mou SS, Giroir BP, Molitor-Kirsch EA, Leonard SR, Nikaidoh H, Nizzi F, et al. Fresh whole blood versus reconstituted blood for pump priming in heart surgery in infants. N Engl J Med. 2004;351:1635-44.

15. Groom RC, Froebe S, Martin J, Manfra MJ, Cormack JE, Morse C, et al. Update on pediatric perfusion practice in North America: 2005 survey. J Extra Corpor Technol. 2005;37:343-50.

16. Bordin JO, Heddle NM, Blajchman MA. Biological effects of leukocytes present in transfused cellular blood products. Blood. 1994;84:1703-21.

17. van de Watering LM, Hermans J, Houbiers JG, van den Broek PJ, Bouter H Boer F, et al. Beneficial effects of leukocyte depletion of transfused blood on postoperative complications in patients undergoing cardiac surgery. Circulation. 1998;97:562-8.

18. Dzik WH. Leukoreduction of blood components. Curr Opin Hematol. 2002;9 521-6.

19. Golan M, Modan M, Lavee J, Martiowitz U, Savion N, Goor DA, et al. Transfusion of fresh whole blood stored $\left(4^{\circ} \mathrm{C}\right)$ for short period fails to improve platelet aggregation on extracellular matrix and clinical hemostasis after cardiopulmonary bypass. J Thorac Cardiovasc Surg. 1990;99:354-60.

20. Koch CG, Li L, Duncan AI, Mihaljevic T, Cosgrove DM, Loop FD, Starr NJ, et al. Morbidity and mortality risk associated with red blood cell and blood component transfusion in isolated coronary artery bypass grafting. Crit Care Med. 2006;34:1608-16.

21. Vamvakas EC, Carven JH. Transfusion and postoperative pneumonia in coronary artery bypass graft surgery: effect of the length of storage of transfused red cells. Transfusion. 1999;39:701-10.

22. Basran S, Frumento RJ, Cohen A, Lee S, Du Y, Nishanian E, et al. The association between duration of storage of transfused red blood cells and morbidity and mortality after reoperative cardiac surgery. Anesth Analg. 2006;103:15-20.

23. Slichter SJ, Davis K, Enright H, Braine H, Gernsheimer T, Kao KJ, et al. Factors affecting posttransfusion platelet increments, platelet refractoriness, and platelet transfusion intervals in thrombocytopenic patients. Blood. 2005; 105:4106-14.

24. Ben-Abraham R, Weinbroum AA, Lotan D, Dagan O, Schreriber-Scheffer R, Mishali $\mathrm{D}$, et al. Interleukin- 8 secretion following cardiopulmonary bypass in children as a marker of early postoperative morbidity. Paediatr Anaesth. 2002;12:156-61. 